\title{
In Vitro Insulin-Like Growth Factor-I, Growth Hormone, and Insulin Resistance Occurs in Symptomatic Human Immunodeficiency Virus-1-Infected Children ${ }^{1}$
}

\author{
MITCHELL E. GEFFNER, DIANA Y. YEH, ELLIOT M. LANDAW, MARILYN L. SCOTT, \\ E. RICHARD STIEHM, YVONNE J. BRYSON, AND VICTOR ISRAELE
}

From the Divisions of Endocrinology [M.E.G., D.Y.Y., M.L.S.], Biomathematics [E.M.L.], Allergy-Immunology [E.R.S.], and Infectious Diseases [Y.J.B.], Department of Pediatrics, UCLA Medical Center and the Division of Infectious Diseases [V.I.], Department of Pediatrics, Cedars-Sinai Medical Center, Los Angeles, California 90024

\begin{abstract}
Poor growth is a common feature of symptomatic children (Centers for Disease Control stage P2) infected with human immunodeficiency virus-1 (HIV-1). However, several previous studies have failed to show any relationship between serum hormone levels and poor growth. To assess the roles of hormone deficiency and hormone resistance in the development of poor growth in HIV-1-infected children, we studied six asymptomatic Centers for Disease Control stage P1 [height SD score = $0.01 \pm 1.0$ (mean \pm SD)], 10 P2 (height SD score $=-2.0$ \pm 1.0 ), and six short, normal children (height SD score = $-2.4 \pm 1.2$ ). Mean weight:height SD scores were similar in all three groups, suggesting that gross nutritional status did not differ between groups. There were no significant differences between groups with respect to mean plasma levels of IGF-I, thyroid hormones, TSH, and cortisol. As an index of hormone sensitivity, we quantified in vitro colony formation of erythroid progenitor cells, isolated from peripheral blood of study subjects, in response to IGF-I, growth hormone (GII), and insulin. P2 subjects had a quantitative mean reduction in erythroid progenitor cells colony formation in response to IGF-I of $32 \%$ compared with $P 1$ subjects ( $p=0.001$ by analysis of variance) and $21 \%$ compared with controls $(p=0.006)$; in response to GH of $21 \%$ compared with controls $(p=0.015)$; and in response to insulin of $35 \%$ compared with PI subjects ( $p$ $=0.038)$ and $34 \%$ compared with controls $(p=0.004)$. Similar qualitative differences (changes in shape) of the three hormone response curves between $\mathrm{P2}$ and $\mathrm{P1}$ and $\mathrm{P2}$ and control subjects were observed. No differences in either quantitative or qualitative erythroid progenitor cells responses to IGF-I, GH, or insulin between P1 and control subjects were observed. We conclude that more severe HIV-1 infection in children is associated with in vitro resistance to the growth-promoting actions of IGF-I, GH, and insulin that is unrelated to the presence of gross malnutrition, differences in hematologic status, or over-
\end{abstract}

Received May 14, 1992; accepted February 18, 1993.

Correspondence and reprint requests: Mitchell E. Geffner, M.D., UCLA Medical Center, Department of Pediatrics, Los Angeles, CA 90024.

Supported by Pediatric AIDS Foundation grants (500017-7-PG and 500103-9PGR) from the American Foundation for AIDS Research (M.E.G.) and by Grant RR-865 from the National Institutes of Health. D. Y. Y. was supported by a Pediatric AIDS Foundation Student Summer Intern Award. E. M. L. w is supported by Grant CA16042 from the National Cancer Institute.

'Presented at the Joint Meetings of the Western Section of the Imerican Federation for Clinical Research, Western Society for Pediatric Resei ch, and Western Region of the Society for Investigative Dermatology, February 1, 1992, and at the Society for Pediatric Research, May 6, 1992. whelming illness. This resistance to IGF-I could contribute to the poor in vivo growth seen in symptomatic HIV-1infected children. (Pediatr Res 34: 66-72, 1993)

\section{Abbreviations}

CDC, Centers for Disease Control

HIV-1, human immunodeficiency virus-1

EPC, erythroid progenitor cell

GH, growth hormone

PAIDS, pediatric AIDS

FTT, failure-to-thrive

$F$, female

M, male

AZT, azidothymidine

CBC, complete blood count

IGF-BP, IGF binding protein

TNF, tumor necrosis factor

$\mathrm{T}_{3}, 3,5,3^{\prime}$-triiodothyronine

$T_{4}$, thyroxine

Whereas infants and children currently constitute $2 \%$ of recognized cases of AIDS in the United States (1), the incidence of HIV-1 infection in this population is rising dramatically. As of July 1990, 2464 children $<13$ y of age met CDC criteria for the diagnosis of AIDS (2). However, from 1988 to 1989, the incidence of AIDS in women and in their offspring increased more rapidly than in any other cohorts; revised predictions suggest that there will be an additional 10000 to 20000 cases of PAIDS in the next few years (3).

The clinical course of infants with vertically transmitted AIDS generally follows one of two paths (4). Approximately $20 \%$ of children infected with HIV-1 develop symptoms in the 1st y of life, with Pneumocystis carinii pneumonia the dominant illness in this group. The more common presentation is late in onset with an asymptomatic period for years. Overt HIV-1 disease develops at a rate of $\sim 8 \% / y$, with a median incubation period of $4.8 \mathrm{y}$; by age $10 \mathrm{y}$, almost all infected children will manifest symptoms (5). Growth retardation, specifically FTT, is a common feature of PAIDS (6), regardless of whether it is acquired by vertical transmission or by transfusion, and is one criterion used to define CDC stage P2 (Table 1) (4). The mechanism for FTT in PAIDS is unknown, although it has been linked to associated malnutrition, hormonal deficiencies, and overwhelming illness (6). However, based on our results from an in vitro 
Table 1. CDC classification system for HIV infection in children under 13 years of age (4)

\begin{tabular}{cc}
\hline Class & Symptom \\
\hline P-0 & Indeterminate infection \\
P-1 & Asymptomatic infection \\
Subclass A & Normal immune function \\
Subclass B & Abnormal immune function \\
Subclass C & Immune function not tested \\
P-2 & Symptomatic infection \\
Subclass A & Nonspecific findings \\
Subclass B & Progressive neurologic disease \\
Subclass C & Lymphoid interstitial pneumo- \\
& nitis \\
Subclass D & Secondary infectious diseases \\
& including opportunistic in- \\
& fections \\
Subclass E & Secondary cancers \\
Subclass F & Other diseases possibly due to \\
& HIV-1 infection \\
\hline
\end{tabular}

EPC colony-forming assay, we propose that this growth retardation may result, at least in part, from resistance to IGF-I.

\section{MATERIALS AND METHODS}

Patients. The study cohort consisted of six asymptomatic P1 children (three $F /$ three $M$ ), 10 symptomatic $P 2$ children (four $F$ / six M), and six short, normal children (two F/four M). Eight PAIDS patients had presumed vertical transmission of their disease based on maternal history (three P1 and five P2), and eight patients became infected after transfusions (three P1 and five P2). All subjects were studied as outpatients. Two P1 and nine $\mathrm{P} 2$ subjects were receiving AZT. No P2 subject was acutely ill at the time of study or had had repeated opportunistic infections. P-staging was according to standardized CDC criteria (4). Short, normal children were, on average, $2.4 \pm 1.2$ (range $=0.6-$ 4.1) SD scores (7) below the mean height for age and had either normal thyroid function tests, normal stimulated serum $\mathrm{GH}$ levels, and/or normal height velocity. Most patients also had $\mathrm{CBC}$ and chemistry panels performed on or near the day of study. All studies were performed with the informed consent and/or assent of the patient and/or his or her parents under a protocol approved by the UCLA Human Subject Protection Committee.

Hormone Assays. Plasma $\mathrm{T}_{4}, \mathrm{~T}_{3}$, reverse $\mathrm{T}_{3}, \mathrm{TSH}$, and cortisol levels were measured between 0800 and $1100 \mathrm{~h}$ by standard RIA. Plasma IGF-I concentrations were determined after acid-ethanol. extraction to remove endogenous IGF-BP. IGF-I levels were normalized for chronologic age by conversion to SD scores (bone ages were not available for children with PAIDS). All hormonal measurements were performed in single assays at Endocrine Sciences Laboratories (Calabasas Hills, CA).

In Vitro Colony Formation of EPC in Response to Stimulation with Hormones. The methodology of the colony-forming assay for EPC is outlined below $(8,9)$. Two 10 -mL samples of venous blood were collected in preservative-free sterile heparin, and buffy coat cells were separated by centrifugation. EPC were cultured in microtiter plates. Recombinant IGF-I [5-100 $\mu \mathrm{g} / \mathrm{L}$ (all concentrations less than are present in normal adult serum)], GH [5-500 $\mu \mathrm{g} / \mathrm{L}$ (serum concentrations $\leq 50 \mu \mathrm{g} / \mathrm{L}$ are considered physiologic)], insulin [860-17200 pmol/L (serum concentrations $\leq 1550 \mathrm{pmol} / \mathrm{L}$ are considered physiologic)], or PBS was added to the cultures. The plates were incubated at $37^{\circ} \mathrm{C}$ in high humidity with $8 \% \mathrm{CO}_{2}$ in air. After 7 to $10 \mathrm{~d}$, the number of large hemoglobinized colonies (burst-forming units) containing $\geq 50$ cells was quantified with an inverted microscope. Infection of myeloid and erythroid progenitor cells with HIV-1 has not been demonstrated $(10,11)$.

Data Analysis. Clinical data are presented as mean $\pm \mathrm{SD}$.
Statistical significance of differences in height, weight, and height:weight SD score, and of CBC and chemistry parameters, serum hormone concentrations, and baseline EPC colony counts between groups, was determined by $t$ test. EPC data are presented as mean \pm SEM to preserve graphic clarity.

Repeated-measures analysis of variance was used to evaluate differences in colony count versus concentration curves among the $\mathrm{P} 1, \mathrm{P} 2$, and short control groups. To accommodate missing data and departures from the usual sphericity assumption, program BMDP5V (BMDP Statistical Software, Inc., Los Angeles, CA) was used to assess group effects and interactions (12). Within each analysis, the Akaike criterion was used to choose among compound symmetry, generalized autoregressive, or full parameterization as the most appropriate covariance model. Two sets of repeated-measures analysis of variance were performed for each of the hormone stimulation studies (IGF-I, GH, or insulin), one to test for qualitative differences in the pattern of stimulation and the second to quantify overall changes in percentage of stimulation. In the first analyses, the dependent variable was the logarithm of the absolute colony count (log count). If differences between curves among P1, P2, and control groups were due only to differences in the baseline number of recovered progenitor cells, the curves would be similar in overall shape and only displaced vertically from one another. Therefore, to test for differences in intrinsic responsiveness to hormone, we looked for differences in shape (e.g. slope or lack of superimposability) of the log count versus concentration curves. Differences in shape indicate that the curves are not superimposable even after correcting for baseline differences in colony counts. Specifically, $p$ values for overall differences in shape were computed by Wald tests for the interaction between group and concentration effects. In the second analyses, changes in responsiveness were quantified by comparing the logarithm of the relative colony counts (expressed as a fraction of the colony count observed at zero concentration). In these analyses, the magnitude of the overall differences in stimulation was assessed by the sizes of the grouping effects (i.e. the mean differences in relative colony counts) and their Wald test $p$ values.

\section{RESULTS}

Patient Clinical Characteristics. The mean age of $\mathbf{P} 2$ patients was younger than that of either the $\mathrm{Pl}(p<0.001)$ or control subjects $(p<0.01)$ (Table 2$)$. The mean height of $\mathrm{P} 2$ patients was shorter than that of $\mathrm{P} 1$ patients $(p<0.001)$, but similar to that of the short, normal controls. The short, normal controls were also shorter than $\mathrm{P} 1$ subjects $(p<0.001)$. The mean weight of $\mathrm{P} 2$ patients was less than that of $\mathrm{P} 1$ patients $(p<0.001)$, but was greater than that of the controls $(p<0.02)$. The short, normal controls also weighed less than P1 subjects $(p<0.001)$. The mean weight:height SD scores were similar among the groups. Equivalency in nutritional status was further supported by lack of difference in concentrations of serum albumin, urea nitrogen, creatinine, and calcium between groups (Table 3 ). In addition, there were no differences in $\mathrm{Hb}$, hematocrit, mean corpuscular $\mathrm{Hb}$, mean corpuscular $\mathrm{Hb}$ concentration, mean corpuscular volume, and erythrocyte count between P1 and P2 subjects and between P1 subjects and short controls. Statistically significant, albeit mild, differences in $\mathrm{Hb}$, hematocrit, mean corpuscular $\mathrm{Hb}$ concentration, mean corpuscular volume, and erythrocyte count between P2 subjects and short controls were observed (Table 3 ).

Plasma Hormone Concentrations. There were no statistically significant mean differences observed in thyroid function tests $\left(T_{4}, T_{3}\right.$, and reverse $T_{3}$ ), TSH, or IGF-I levels (as in index of GH sufficiency) between P1, P2, and control groups (Table 4). Additionally, mean basal plasma cortisol levels did not differ significantly between groups. Failure to observe differences between groups in plasma IGF-I, reverse $\mathrm{T}_{3}$, and cortisol levels also 
Table 2. Patient clinical characteristics*

\begin{tabular}{|c|c|c|c|c|c|c|}
\hline \multirow[b]{2}{*}{ Characteristic } & \multirow[b]{2}{*}{$\mathrm{Pl}(n=6)$} & \multirow[b]{2}{*}{$\mathrm{P} 2(n=10)$} & \multirow[b]{2}{*}{$C(n=6)$} & \multicolumn{3}{|c|}{$p$} \\
\hline & & & & $\mathrm{Pl}$ vs $\mathrm{C}$ & $\mathrm{P} 2$ vs $\mathrm{C}$ & $\mathrm{P} 1$ vs $\mathrm{P} 2$ \\
\hline Age $(y)$ & $8.1 \pm 4.0$ & $4.7 \pm 2.8$ & $6.4 \pm 2.9$ & NS & $<0.01$ & $<0.001$ \\
\hline Height SD score & $0.01 \pm 1.0$ & $-2.0 \pm 1.0$ & $-2.4 \pm 1.2$ & $<0.001$ & NS & $<0.001$ \\
\hline Weight SD score & $1.5 \pm 1.0$ & $-1.2 \pm 1.1$ & $-1.9 \pm 1.4$ & $<0.001$ & $<0.02$ & $<0.001$ \\
\hline Weight:height SD score & $0.7 \pm 1.0$ & $0.6 \pm 0.7$ & $0.5 \pm 0.8$ & NS & NS & NS \\
\hline
\end{tabular}

* Values are mean $\pm \mathrm{SD}$. $C$, control.

Table 3. Chemistry and hematologic data*

\begin{tabular}{|c|c|c|c|}
\hline & $\mathrm{Pl}$ & P2 & Control \\
\hline \multicolumn{4}{|l|}{ Chemistry } \\
\hline Albumin $(\mathrm{g} / \mathrm{L})$ & $46 \pm 3.4 \quad(n=4)$ & $45 \pm 5.7 \quad(n=6)$ & $49 \pm 2.5 \quad(n=4)$ \\
\hline Urea nitrogen $(\mathrm{mmol} / \mathrm{L})$ & $3.5 \pm 2.4 \quad(n=4)$ & $3.6 \pm 2.1 \quad(n=7)$ & $4.6 \pm 1.5 \quad(n=4)$ \\
\hline Creatinine $(\mu \mathrm{mol} / \mathrm{L})$ & $60 \pm 13 \quad(n=4)$ & $51 \pm 0.2 \quad(n=6)$ & $57 \pm 5.3 \quad(n=4)$ \\
\hline Calcium $(\mathrm{mmol} / \mathrm{L})$ & $2.4 \pm 0.1 \quad(n=4)$ & $2.4 \pm 0.2 \quad(n=6)$ & $2.5 \pm 0.04(n=4)$ \\
\hline \multicolumn{4}{|l|}{ Hematology } \\
\hline $\mathrm{Hb}(\mathrm{mmol} / \mathrm{L})$ & $7.1 \pm 0.7 \quad(n=6)$ & $6.7 \pm 0.7 \quad(n=8) \dagger$ & $8.2 \pm 0.8 \quad(n=4)$ \\
\hline Het & $0.34 \pm 0.03(n=6)$ & $0.32 \pm 0.04(n=9) \ddagger$ & $0.38 \pm 0.03(n=4)$ \\
\hline $\mathrm{MCH}(\mathrm{pg} /$ cell $)$ & $33 \pm 2.7 \quad(n=6)$ & $32 \pm 3.1 \quad(n=9)$ & $34 \pm 0.6 \quad(n=3)$ \\
\hline $\mathrm{MCHC}(\mathrm{g} / \mathrm{L})$ & $318 \pm 30 \quad(n=6)$ & $329 \pm 18 \quad(n=9) \S$ & $284 \pm 9.1 \quad(n=3)$ \\
\hline $\operatorname{MCV}(\mathrm{fL})$ & $90 \pm 9.7 \quad(n=6)$ & $92 \pm 7.6 \quad(n=9) \ddagger$ & $82 \pm 4.5 \quad(n=4)$ \\
\hline Erythrocyte count $\left(\times 10^{12} / \mathrm{L}\right)$ & $3.7 \pm 0.5 \quad(n=6)$ & $3.5 \pm 0.6 \quad(n=8) \ddagger$ & $4.6 \pm 0.7 \quad(n=3)$ \\
\hline
\end{tabular}

*Values are mean \pm SD. Hct, hematocrit; MCH, mean corpuscular Hb; MCHC, mean corpuscular Hb concentration; MCV, mean corpuscular volume.

$\dagger p<0.02$ vs control.
$\ddagger p<0.05$ vs control.
$\S p<0.01$ vs control.

Table 4. Hormonal concentrations*

\begin{tabular}{lccc}
\hline \multicolumn{1}{c}{ Hormone (units) } & P1 $(n=4)$ & P2 $(n=9)$ & Control $(n=4)$ \\
\hline IGF-I (SD score) $\dagger$ & $-1.28 \pm 0.22$ & $-1.77 \pm 0.20$ & $-1.05 \pm 0.77$ \\
$\mathrm{~T}_{4}(\mathrm{nmol} / \mathrm{L})$ & $106 \pm 9.5$ & $111 \pm 23$ & $97.8 \pm 5.2$ \\
$\mathrm{~T}_{3}(\mathrm{nmol} / \mathrm{L})$ & $2.4 \pm 0.5$ & $2.3 \pm 0.5$ & $2.2 \pm 0.3$ \\
Reverse $\mathrm{T}_{3}(\mathrm{pmol} / \mathrm{L})$ & $419 \pm 52$ & $338 \pm 149$ & $392 \pm 60$ \\
$\mathrm{TSH}(\mathrm{mU} / \mathrm{L})$ & $1.4 \pm 0.2$ & $2.5 \pm 0.4$ & $2.6 \pm 1.0$ \\
Cortisol (nmol/L) & $174 \pm 30$ & $295 \pm 188$ & $348 \pm 196$ \\
\hline
\end{tabular}

$*$ Values are mean \pm SD.

† IGF-I levels were normalized for chronologic age by conversion to SD scores.

suggests that there were no gross or subtle nutritional differences between groups.

In Vitro Hormone Responsiveness. General. Eight EPC studies of six P1 subjects, 11 studies of $10 \mathrm{P} 2$ subjects, and six studies (one each) of six short, normal control subjects were performed. For those subjects studied on two occasions, mean responsiveness is reported.

IGF-I. Basal colony counts (without added hormone) for experiments with IGF-I were $98.0 \pm 43(\mathrm{P} 1), 52.6 \pm 25$ (P2), and $41.8 \pm 10.5$ (control); $\mathrm{P} 1$ versus $\mathrm{P} 2(p<0.02), \mathrm{P} 1$ versus control $(p<0.01)$, and P2 versus control $(p=\mathrm{NS})$. The overall shape of the EPC colony formation curve of P2 subjects in response to direct IGF-I stimulation was qualitatively different from that of $\mathrm{PI}$ subjects and that of controls (both $p<0.001$ ). The shapes of the curves for P1 subjects and controls were comparable and were superimposable after correcting for differences in baseline colony counts $(p=0.1)$ (Fig. 1A, absolute data). P2 subjects had a significant mean reduction in EPC colony formation in response to IGF-I of $32 \%$ compared with P1 subjects $(p=0.001)$ and of $21 \%$ compared with controls $(p$ $=0.006$ ). There was no statistically significant difference between Pl subjects and controls $(p=0.67)$ (Fig. 1B, relative data).

GII. Basal colony counts for experiments with GH were 87.6 $\pm 45(\mathrm{P} 1), 48.8 \pm 22(\mathrm{P} 2)$, and $41.5 \pm 10.2$ (control); $\mathrm{Pl}$ versus $\mathrm{P} 2(p<0.05), \mathrm{P} 1$ versus control $(p<0.05)$, and $\mathrm{P} 2$ versus control ( $p=\mathrm{NS}$ ). The overall shape of the EPC colony formation curve of $\mathrm{P} 2$ subjects in response to $\mathrm{GH}$ was qualitatively different compared with that of controls $(p=0.009)$ and showed a borderline difference compared with that of P1 subjects $(p=$ 0.057). The shapes of the curves for P1 subjects and controls were similar ( $p=0.72$ ) (Fig. $2 A$, absolute data). P2 subjects had a significant mean reduction in EPC colony formation in response to $\mathrm{GH}$ of $21 \%$ compared with controls $(p=0.015)$. P2 subjects had a mean reduction in EPC colony formation in response to $\mathrm{GH}$ of $16 \%$ compared with $\mathrm{P} 1$ subjects $(p=0.128)$. There was no statistically significant difference between $\mathrm{P} 1$ subjects and controls $(p=0.42)$ (Fig. $2 B$, relative data).

Insulin. Basal colony counts for experiments with insulin were $107 \pm 64$ (P1), $55.6 \pm 26$ (P2), and $40.5 \pm 10.2$ (control); P1 versus $\mathrm{P} 2(p<0.05), \mathrm{P} 1$ versus control $(p<0.05)$, and $\mathrm{P} 2$ versus control ( $p=\mathrm{NS}$ ). The overall shape of the EPC colony formation curve of P2 subjects in response to insulin was qualitatively different compared with that of $\mathrm{P} 1$ subjects $(p=0.007)$ and that of controls $(p=0.001)$. The shapes of the curves for P1 subjects and controls were similar ( $p=0.69$ ) (Fig. $3 A$, absolute data). P2 subjects had a significant mean reduction in EPC colony formation in response to insulin stimulation of $35 \%$ compared with P1 subjects $(p=0.038)$ and of $34 \%$ compared with controls ( $p$ $=0.004$ ); there was no statistically significant difference between P1 subjects and controls $(p=0.47)$ (Fig. $3 B$, relative data).

Effects of $A Z T$. Because many of the PAIDS patients (both P1 and P2) were on AZT at the time of study, the in vitro effect of AZT incubation [at either 2 or $5 \mu \mathrm{M}$ (therapeutic serum concentrations)] on normal EPC responsiveness to IGF-I, GH, and insulin was assessed. Neither concentration of AZT induced significant blunting of EPC responsiveness to any of the three growth factors (data not shown).

\section{DISCUSSION}

Resistance to IGF-I, GH, and other growth factors has been previously suggested as a potential cause for growth failure in children with AIDS $(13,14)$. Such resistance can result from 
A. IGF-1: Absolute

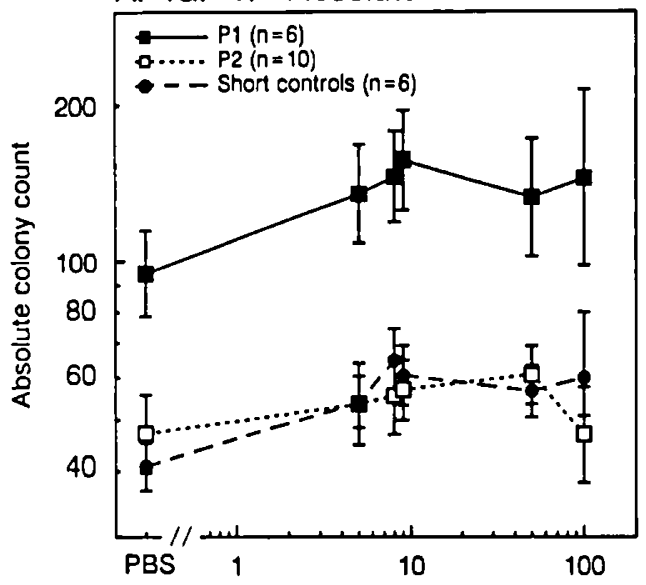

B. IGF-1: Relative

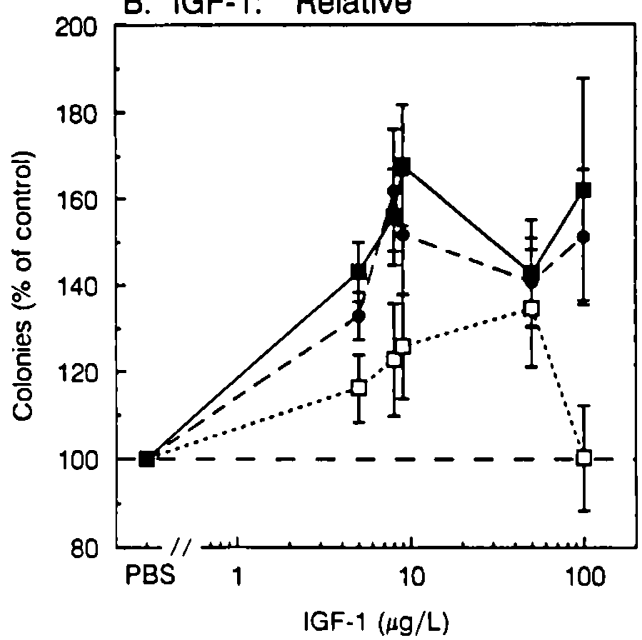

Fig. 1. EPC responsiveness to IGF-I. $A$, Absolute data. The overall shape of the EPC colony formation curve of $P 2$ subjects in response to direct IGF-I stimulation was qualitatively different compared with that of Pl subjects and controls (both $p<0.001$ ). The shapes of the curves for Pl subjects and controls were similar $(p=0.1)$; i.e. the slopes were comparable and the curves were superimposable after correcting for baseline differences. The ordinate is on a log scale and represents the absolute number of erythroid colonies formed in response to increasing concentrations of IGF-I. The abscissa here and in $B$ represents the concentrations of added IGF-I $(\mu \mathrm{g} / \mathrm{L})$. The data here and in the subsequent two figures are presented as the mean \pm SEM of the log counts. Key for this and the subsequent two figures: $P$ l, asymptomatic HIV-1infected children; $P 2$, symptomatic HIV-1-infected children [specific $P$ staging criteria based on standardized CDC criteria (4); see Table 1]; short controls, short, endocrinologically normal children. $B$, Relative data. P2 subjects had a significant mean reduction in EPC colony formation in response to direct IGF-I stimulation of $32 \%$ compared with Pl subjects $(p=0.001)$ and of $21 \%$ compared with controls $(p=0.006)$; there was no statistically significant difference between $\mathrm{Pl}$ subjects and controls $(p=0.67)$. The unstimulated number of EPC colonies (referred to, on the ordinate, as colonies) formed in incubation mixtures without added IGF-I is defined as $100 \%$.

prereceptor, receptor-binding, or post-receptor-binding abnormalities. In the current study, we have shown that symptomatic children with AIDS (CDC stage P2) demonstrate marked in vitro resistance to the growth-promoting action of IGF-I compared with asymptomatic (P1) children with AIDS and compared with equally short, otherwise normal children. The P2 children also manifested a statistically significant reduction in in vitro responsiveness to the growth-promoting action of $\mathrm{GH}$ compared with short controls. Compared with P1 children, responsiveness of P2
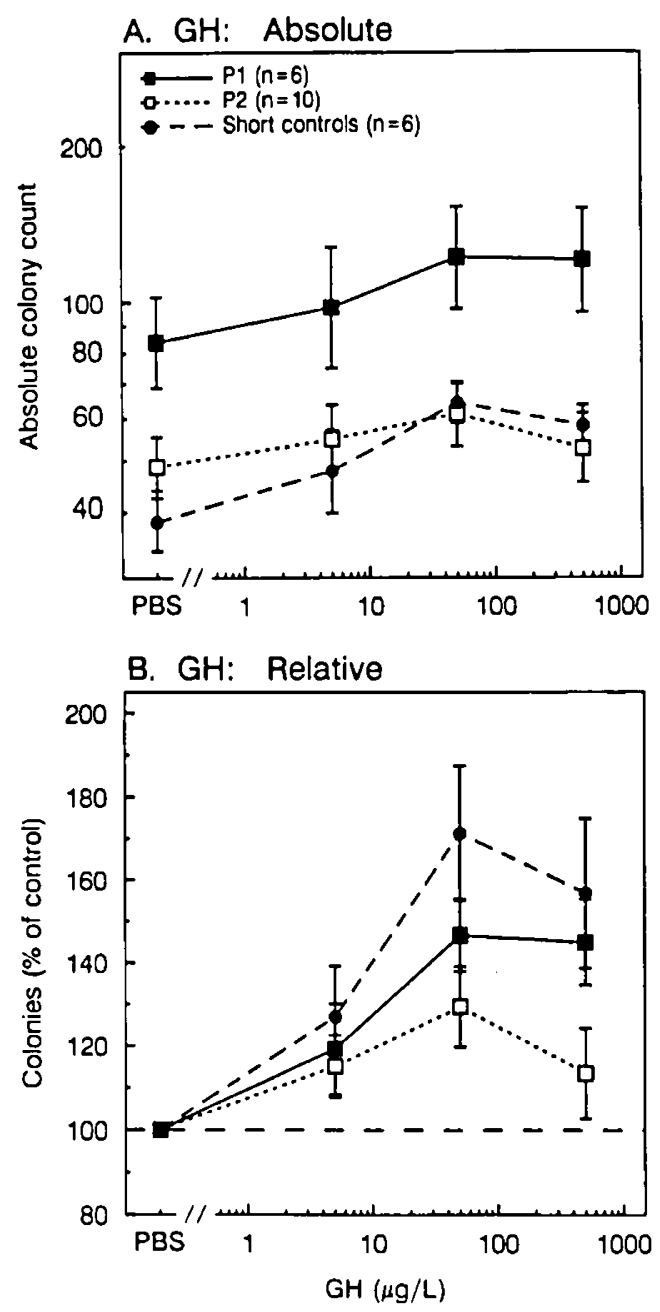

Fig. 2. EPC responsiveness to GH. $A$, Absolute data. The overall shape of the EPC colony formation curve of $\mathrm{P} 2$ subjects in response to $\mathrm{GH}$ stimulation was qualitatively different compared with that of controls $(p=0.009)$ and showed a borderline difference compared with that of P1 subjects $(p=0.057)$. The shapes of the curves for P1 subjects and controls were similar $(p=0.72)$. The ordinate is on a log scale and represents the absolute number of erythroid colonies formed in response to increasing concentrations of $\mathrm{GH}$. The absciss $a$ here and in $B$ represents the concentrations of added $\mathrm{GH}(\mu \mathrm{g} / \mathrm{L}) . B$, Relative data. P2 subjects had a significant mean reduction in EPC colony formation in response to $\mathrm{GH}$ of $21 \%$ compared with controls ( $p=0.015$ ). P2 subjects had a mean reduction in EPC colony formation in response to $\mathrm{GH}$ of $16 \%$ compared with P1 subjects $(p=0.128)$. There was no statistically significant difference between $\mathrm{Pl}$ subjects and controls $(p=0.42)$. The unstimulated number of erythroid progenitor cell colonies (referred to, on the ordinate, as colonies) formed in incubation mixtures without added $\mathrm{GH}$ is defined as $100 \%$.

children to $\mathrm{GH}$ showed a borderline reduction. Because the effect of $\mathrm{GH}$ on normal erythropoiesis appears to be mediated through local IGF-I production and action (15), one might expect there to be $\mathrm{GH}$ resistance in situations in which there is IGF-I resistance. As a paradigm for this interaction, both GH and IGF-I resistance have been described in association with protein malnutrition in rats $(16,17)$. In addition, statistically significant resistance to the mitogenic action of insulin was observed in P2 subjects compared with both P1 subjects and controls. The statistically significant findings of resistance to the growth-promoting actions of IGF-I, GH, and insulin were evident regardless of whether logs of the absolute count (changes in shape) or relative data (quantitative) were analyzed.

The observed differences in basal colony formation between 

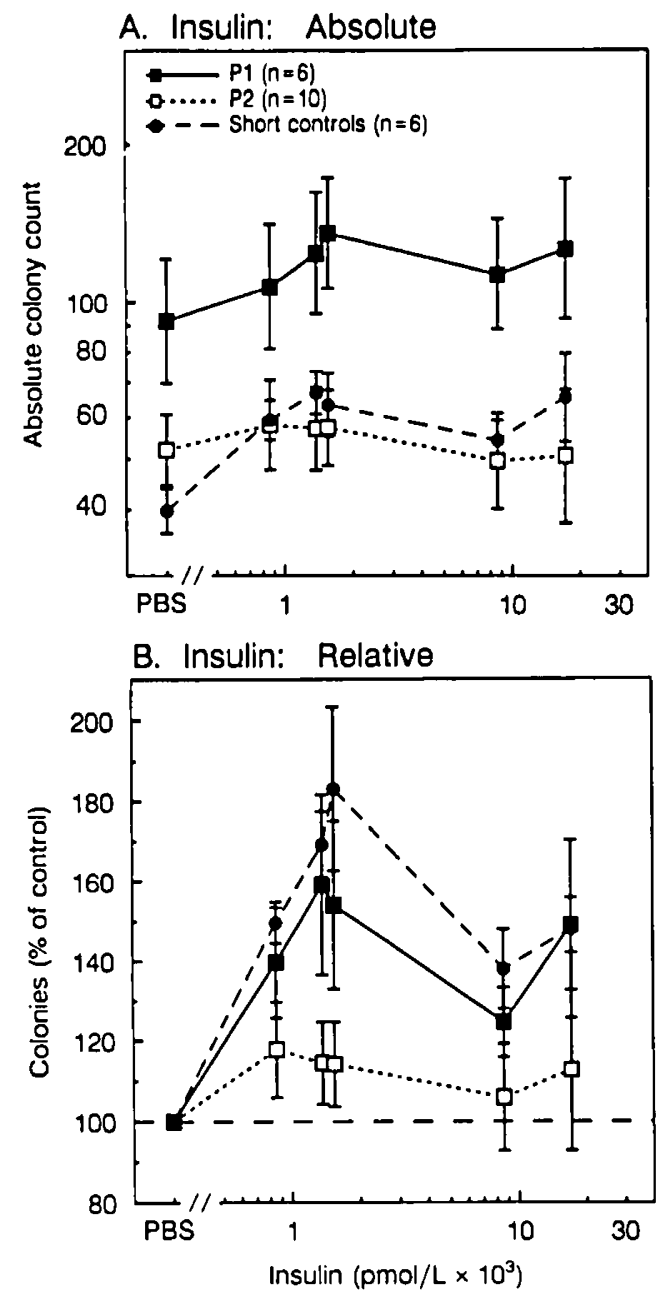

Fig. 3. EPC responsiveness to insulin. $A$, Absolute data. The overall shape of the EPC colony formation curve of $P 2$ subjects in response to insulin stimulation was qualitatively different compared with that $\mathrm{P} 1$ subjects $(p=0.007)$ and controls $(p=0.001)$. The shapes of the curves for P1 subjects and controls were similar $(p=0.69)$. The ordinate is on a log scale and represents the absolute number of erythroid colonies formed in response to increasing concentrations of insulin. The abscissa here and in Figure $1 C$ represents the concentrations of added insulin $\left(\mathrm{pmol} / \mathrm{L} \times 10^{3}\right) . B$, Relative data. $\mathrm{P} 2$ subjects had a significant mean reduction in EPC colony formation in response to insulin stimulation of $35 \%$ compared with P1 subjects $(p=0.038)$ and of $34 \%$ compared with controls $(p=0.004)$; there was no statistically significant difference between $\mathrm{P} 1$ subjects and controls $(p=0.47)$. The unstimulated number of erythroid progenitor cell colonies (referred to, on the ordinate, as colonies) formed in incubation mixtures without added insulin is defined as $100 \%$.

P1 patients and the other two groups, although statistically significant, are not likely to account for differences in stimulatory responses based on previous studies from our laboratory; furthermore, there were no significant differences in basal colony formation between P2 subjects and controls, yet there were significant differences in responsiveness to all three growth factors. It is unclear why Pl subjects had significantly higher basal colony counts compared with the other two groups. Although P2 and control subjects had a similar degree of growth failure, short stature per se is not associated with lower basal colony counts (18). Furthermore, we have shown in this study that AZT treatment does not influence the magnitude of EPC colony formation in response to IGF-I, GH, or insulin. The observed differences in IGF-I responsiveness between $\mathrm{P} 2$ subjects and short controls are also not likely to be due to minor differences in the erythroid status between these two groups in view of similar differences in IGF-I responsiveness between $P 1$ and $P 2$ subjects whose erythroid parameters were statistically indistinguishable.

Recently, Laurence et al. (19) have shown that GH, depending on the concentration used, enhances HIV-1 replication in acutely infected peripheral blood mononuclear cells as measured by p24 antigen production, cellular proliferation $\left(\left[{ }^{3} \mathrm{H}\right]\right.$ thymidine incorporation), and TNF- $\alpha$ production. However, in the same study, a clone of chronically HIV-1-infected promonocytic cells, sensitive to viral induction by cytokines and protein kinase $\mathrm{C}$ activators, was resistant to the effects of $\mathrm{GH}$ on p24 antigen production and on HIV-1-associated trans-activation (19). If the latent infection is more reflective of in vivo HIV-1 infection, these data would be consistent with our findings of GH/IGF-I resistance.

The IGF-I-resistant P2 patients in this study were significantly shorter than the asymptomatic P1 patients and the short, normal children. We found no differences between groups in thyroid function or in plasma IGF-I levels as an index of GH sufficiency. Low plasma IGF-I levels have been reported frequently, but not always, in children with $\operatorname{AIDS}(6,13)$ and are thought to be the result of associated malnutrition. Gross malnutrition was not likely to be responsible for the IGF-I resistance observed in our P2 subjects inasmuch as their mean weight SD score was similar to that of our IGF-I-sensitive short, normal control group. Whereas sophisticated tests of body composition were not used in this study, lack of difference in various sensitive chemical and endocrinologic measures of nutritional status also suggests that the differences in in vitro hormone responsiveness are not the result of differences in body composition between groups. Nonetheless, a highly selective nutritional deficiency as may occur in AIDS patients (20) cannot be excluded as at least a partial explanation for our observations. Normal serum $T_{4}$ and $T_{3}$ levels and normal stimulated $\mathrm{GH}$ levels have been reported in most children with AIDS $(13,14)$. A single child with perinatally acquired HIV-1 infection with well-characterized GH deficiency in the face of poor linear growth velocity and delayed bone age whose height velocity nearly doubled with GH treatment (although to a rate considerably less than is usually seen in other situations associated with $\mathrm{GH}$ deficiency) has been described (21).

The mechanism by which IGF-I resistance develops could be related to increased production of cytokines, which occurs in patients with AIDS. Specifically, TNF production is increased in some AIDS patients, particularly in the setting of opportunistic infections, progressive encephalopathy, and wasting (22). Whereas IGF-I has been shown to promote human adult and embryonic erythropoiesis, TNF inhibits erythroid colony formation at a concentration of $\sim 10 \mathrm{U} / \mathrm{mL}$ (23). Chronic TNFinduced inhibition of erythropoiesis has been suggested as a cause for the hypoplastic anemia that occurs in AIDS patients (24). However, IGF-I (10-100 $\mu \mathrm{g} / \mathrm{L})$ promotes cartilage matrix formation (proteoglycan synthesis) equally in the presence or absence of TNF (5-500 pmol/L) (25). Thus, the in vitro cellular resistance to IGF-I demonstrated in our P2 subjects is unlikely to be a TNF-induced epiphenomenon. Other cytokines, e.g. IL1 and interferon- $\gamma$, do not appear to exert pronounced inhibitory actions in the above systems. Most recently, elevated serum interferon- $\alpha$ levels have been described in patients with AIDS and have been implicated at least in the hypertriglyceridemia associated with wasting (26). However, none of our P2 subjects was acutely ill and, therefore, their blunted EPC responsiveness to the three growth factors is not likely to be the result of severe intercurrent illness.

One mechanism whereby GH and IGF-I resistance could occur in children with symptomatic AIDS is through the presence of circulating inhibitors of IGF-I action, such as IGF-BP. Six such proteins have now been described, although the majority of IGF in the circulation are associated with a single $150-\mathrm{kD}$ complex known as IGF-BP3, levels of which are strongly GH-dependent (27). A second, presumably non-GH-dependent IGF-BP is IGF- 
BP1. Purified IGF-BP1 inhibits serum IGF-I-stimulated and basal cartilage sulfation in vitro in a dose-dependent manner. A positive correlation has been reported between circulating levels of IGF-BPI and serum IGF-I inhibitory bioactivity in diabetic sera, suggesting that IGF-I resistance might underlie delayed growth sometimes seen in diabetic adolescents (28). Resistance to IGF-I has also been proposed as contributing to the growth retardation associated with the Mauriac syndrome of diabetes (29). In addition, several children with isolated short stature have been reported who had apparent resistance to IGF-I in association with elevated serum IGF-I concentrations as measured either by RIA, radioreceptor assay, and/or bioassay (30-32). One of these children manifested a 50\% reduction in IGF-I binding to her fibroblasts (31), whereas a second child's fibroblasts were resistant to IGF-I because of abnormal production and/or cell association of IGF-BP $(32,33)$. There are no data as yet evaluating the relationship between cytokines and IGF-BP. Our finding of in vitro resistance to the mitogenic action of insulin in P2 subjects is supported by in vivo data that show that prolonged infusion of TNF to rats impairs both suppression of hepatic glucose production and peripheral glucose utilization (34). However, in one study of clinically stable, symptomatic HIV-1infected men, increased insulin sensitivity of peripheral tissues with regard to glucose metabolism was reported (35).

Although traditional hormonal-resistance states are associated with compensatorily elevated plasma levels of the specific hormonal signal, we found nonelevated plasma levels of IGF-I in the face of IGF-I resistance. Our failure to find elevated plasma IGF-I levels could reflect chronicity of the resistance (leading to fatigue of the GH-IGF-I axis similar to the development of hypoinsulinemia, which frequently occurs in severe type 2 diabetes) (36), local tissue versus systemic resistance to IGF-I (thus not reflected as an elevation of the plasma IGF-I level), or changes in IGF-BP. In addition, the elevated serum GH levels characteristic of children with genetic $\mathrm{GH}$ resistance (Laron dwarfism) are much reduced in adulthood (37). In addition, Pygmies secrete normal amounts of $\mathrm{GH}$ after provocative stimuli despite in vitro evidence of $\mathrm{GH}$ resistance (38). Finally, end-organ resistance to IGF-I without elevated serum IGF-I levels has been suggested as a cause for the short stature of girls with Turner syndrome (39).

Both GH and IGF-I are immunomodulators. Whereas treatment with $\mathrm{GH}$ in some studies has been associated with a diminution in immunologic function (40-42) and in other studies with no significant persistent effect on the immune system (43-45), GH may enhance T-cell proliferation $(46,47)$, augment T-cell number (48), and increase natural killer cell activity (49, 50). Additionally, GH causes stimulation of in vitro proliferation of normal and some leukemic human T-lymphocytes (51). Finally, normal human T-lymphocytes transformed with either human T-cell lymphotrophic virus-1 or -2 show augmentation of basal colony formation in response to $\mathrm{GH}$, its local mediator IGF-I, and insulin, another growth factor of childhood $(8,9)$.

IGF-I also appears to have immunologic activity, either directly at physiologic concentrations (52) or as the local mediator of GH action (53). Administration of IGF-I increases thymic and splenic weight in hypophysectomized rats (54) and induces repopulation of the atrophied thymus in diabetic rats (55). Both IGF-I and GH stimulate thymulin secretion by, and proliferation of, thymic epithelial cells (56). Thus, IGF-I resistance could contribute to the immunodeficiency seen in AIDS patients. Recently, short-term GH administration to HIV-1-positive men has been shown to exert anabolic actions, including reversal of weight loss, improvement of body composition and functional capacity, and increase of protein-sparing fatty acid oxidation (57, 58), suggesting retention of responsiveness to certain actions of $\mathrm{GH}$. GH also appears to partially counteract the myelosuppressive effects of AZT in normal mice and, for this reason, it may have additional clinical benefit in patients with AIDS (59). Whether there is immunologic resistance to IGF-I in patients with AIDS and whether it can be overcome by administration of GH or IGF-I requires further study.

Acknowledgments. The authors thank Leslie Spring; Sheila Gillespie-Gillette, R.N., C., M.S.N., F.N.P.; Dale Perry, R.N., C., M.S.N., F.N.P.; and Teresa Courville, R.N., M.N. for their collaboration and helpful comments.

\section{REFERENCES}

1. MacDonald MG, Ginzburg HM, Bolan JC 1991 HIV infection in pregnancy: epidemiology and clinical management. J Acquired Immun Defic Syndr 4:100-108

2. Centers for Disease Control 1990 HIV/AIDS Surveillance Report. August 1990, Atlanta

3. Rossi P, Moschese V 1991 Mother-to-child transmission of human immunodeficiency virus. FASEB J 5:2419-2426

4. Grubman S, Conviser R, Oleske J 1992 HIV infection in infants, children, and adolescents. In: Wormser GP (ed) AIDS and Other Manifestations of HIV Infection. Raven, New York, pp 201-216

5. Auger I, Thomas P, De Gruttola V, Morse D, Moore D, Williams R, Truman $B$, Lawrence CE 1988 Incubation periods for paediatric AIDS patients. Nature 336:575-577

6. Lepage $P$, Van de Perre P, Van Vliet G, Nsengumuremyi F, Van Goethem $C$ Kestelyn P, Msellati P, Hitimana D-G 1991 Clinical and endocrinological manifestations in perinatally human immunodeficiency virus type 1-infected children aged 5 years or older. Am J Dis Child 145:1248-1251

7. Hammill PVV, Drizd TA, Johnson CL, Reed RB, Roche AF 1977 NCHS growth curves for children. National Center for Health Statistics (DHEW publication no. [PHS]78-1650. Vital and Health Statistics: Series 11, No 165), Hyattsville, MD

8. Geffner ME, Golde DW, Lippe BM, Kaplan SA, Bersch N, Li CH 1987 Tissues of the Laron dwarf are sensitive to insulin-like growth factor 1 but not to growth hormone. J Clin Endocrinol Metab 64:1042-1046

9. Geffner ME, Kaplan SA, Bersch N, Lippe BM, Smith WG, Nagel RA, Santulli $\mathrm{Jr} \mathrm{TV}, \mathrm{Li} \mathrm{CH}$, Golde DW 1987 Leprechaunism: in vitro insulin action despite genetic insulin resistance. Pediatr Res 22:286-291

10. Molina J-M, Scadden DT, Sakaguchi M, Fuller B, Won A, Groopman JE 1990 Lack of evidence for infection of or effect on growth of hematopoietic progenitor cells after in vivo or in vitro exposure to human immunodeficiency virus. Blood 76:2476-2482

11. Davis BR, Schwartz DH, Marx JC, Johnson CE, Berry JM, Lyding J, Merigan TC, Zander A 1991 Absent or rare human immunodeficiency virus infection of bone marrow stem/progenitor cells in vivo. J Virol 65:1985-1990

12. Dixon WJ (ed) 1990 BMDP Statistical Software Manual. University of California Press, Berkeley, CA, pp 1207-1244

13. Schwartz LJ, St. Louis Y, Wu R, Wiznia A, Rubinstein A, Saenger P 1991 Endocrine function in children with human immunodeficiency virus infection. Am J Dis Child 145:330-333

14. Laue L, Pizzo PA, Butler K, Cutler Jr GB 1990 Growth and neuroendocrine dysfunction in children with acquired immunodeficiency syndrome. J Pediatr 117:541-545

15. Merchav S, Tatarsky I, Hochberg Z 1988 Enhancement of erythropoiesis in vitro by human growth hormone is mediated by insulin-like growth factor 1. Br J Haematol 70:267-271

16. Thissen J-P, Triest S, Underwood LE, Maes M, Ketelslegers J-M 1990 Divergent responses of serum insulin-like growth factor-1 (IGF-1) and liver growth hormone $(\mathrm{GH})$ receptors to exogenous $\mathrm{GH}$ in protein-restricted rats. Endocrinology 126:908-913

17. Thissen J-P, Underwood LE, Maiter D, Maes M, Clemmons DR, Ketelsiegers J-M 1991 Failure of insulin-like growth factor-1 (IGF-1) infusion to promote growth in protein-restricted rats despite normalization of serum IGF-1 concentrations. Endocrinology 128:885-890

18. Barak Y, Zadik Z, Karov Y, Hahn T 1992 Enhanced response of human circulating erythroid progenitor cells to hGH and to IGF-I in children with insufficient growth hormone secretion. Pediatr Res 32:282-285

19. Laurence J, Grimison B, Gonenne A 1992 Effect of recombinant human growth hormone on acute and chronic human immunodeficiency virus infection in vitro. Blood 79:467-472

20. Kotler DP 1989 Malnutrition in HIV infection and AIDS. AIDS 3(suppl 1):S175-S180

21. Jospe N, Powell KR 1990 Growth hormone deficiency in an 8-year-old girl with human immunodeficiency virus infection. Pediatrics $86: 309-312$

22. Remick DG 1991 Significance of in vivo detection of tumor necrosis factor. Lab Invest 65:259-261

23. Migliaccio AR, Migliaccio G 1988 Human embryonic hemopoiesis: control mechanisms underlying progenitor differentiation in vitro. Dev Bio 125:127-134

24. Odeh M 1990 The role of tumor necrosis factor- $\alpha$ in acquired immunodeficiency syndrome. J Int Med 228:549-556

25. Tyler JA 1989 Insulin-like growth factor 1 can decrease degradation and promote synthesis of proteoglycan in cartilage exposed to cytokines. Biochem J 260:543-548

26. Grunfeld C, Kotler DP, Shigenaga JK, Doerrler W, Tierney A, Wang J, Person Jr RN, Feingold KR 1990 Circulating interferon alpha levels and hypertrig- 
lyceridemia in the acquired immunodeficiency syndrome. Am J Med 90:154-162

27. Ooi GT 1990 Insulin-like growth factor-binding proteins (IGFBPs): more than just 1,2,3. Mol Cell Endocrinol 71:C39-C43

28. Taylor AM, Dunger DB, Preece MA, Holly JMP, Smith CP, Wass JAH, Patel $S$, Tate VE 1990 The growth hormone independent insulin-like growth factor-1 binding protein BP-28 is associated with serum insulin-like growth factor- 1 inhibitory bioactivity in adolescent insulin-dependent diabetics. Clin Endocrinol 32:229-239

29. Mauras N, Merimee T, Rogol AD 1991 Function of the growth hormoneinsulin-like growth factor 1 axis in the profoundly growth-retarded diabetic child: evidence for defective target organ responsiveness in the Mauriac syndrome. Metabolism 40:1106-1111

30. Lanes R, Plotnick LP, Spencer EM, Daughaday WH, Kowarski AA 1980 Dwarfism associated with normal serum growth hormone and increased bioassayable, radio-receptorassayable, and immunoassayable somatomedin. $\mathrm{J}$ Clin Endocrinol Metab 50:485-488

31. Bierich JR, Moeller H, Ranke MB, Rosenfeld RG 1984 Pseudopituitary dwarfism due to resistance to somatomedin: a new syndrome. Eur J Pediatr 142:186-188

32. Heath-Monnig E, Wohltmann HJ, Mills-Dunlap B, Daughaday WH 1987 Measurement of insulin-like growth factor (IGF-1) responsiveness of fibroblasts of children with short stature: identification of a patient with IGF-1 resistance. J Clin Endocrinol Metab 64:501-506

33. Tollefsen SE, Heath-Monnig E, Cascieri MA, Bayne ML, Daughaday WH 1991 Endogenous insulin-like growth factor (IGF) binding proteins cause IGF-1 resistance in cultured fibroblasts from a patient with short stature. J Clin Invest 87:1241-1250

34. Lang CH, Dobrescu C, Bagby GJ 1992 Tumor necrosis factor impairs insulin action on peripheral glucose disposal and hepatic glucose output. Endocrinology 130:43-52

35. Hommes MJT, Romijn JA, Endert E, Karel J, Schattenkerk ME, Sauerwein H 1991 Insulin sensitivity and insulin clearance in human immunodeficiency virus type 1 -infected men. Metabolism 40:651-656

36. Saad MF, Knowler WC, Pettitt DJ, Nelson RG, Mott DM, Bennett PH 1989 Sequential changes in serum insulin concentration during development of non-insulin-dependent diabetes. Lancet 1:1356-1359

37. Laron Z 1984 Laron-type dwarfism (hereditary somatomedin deficiency): a review. Adv Intern Med Pediatr 54:117-150

38. Merimee TJ 1989 Growth hormone and IGF abnormalities of the African Pygmy. In: Leroith D, Raizada MK (eds) Molecular and Cellular Biology of Insulin-Like Growth Factors and Their Receptors. Plenum Press, New York, pp 73-80

39. Zadik Z, Landau H, Chen M, Altman Y, Lieberman E 1992 Assessment of growth hormone $(\mathrm{GH})$ axis in Turner's syndrome using 24-hour integrated concentrations of $\mathrm{GH}$, insulin-like growth factor-1, plasma GH-binding activity, $\mathrm{GH}$ binding to IM9 cells, and $\mathrm{GH}$ response to pharmacological stimulation. J Clin Endocrinol Metab 75:412-416

40. Rapaport R, Oleske J, Ahdieh H, Solomon S, Delfaus C, Denny T 1986 Suppression of immune function in growth hormone-deficient children during treatment with human growth hormone. J Pediatr 109:434-439

41. Kiess W, Doerr H, Eisl E, Butenandt O, Belohradsky BH 1986 Lymphocyte subsets and natural-killer activity in growth hormone deficiency. $N$ Engl $J$ Med 314:321-322

42. Petersen BH, Rapaport R, Henry DP, Huseman C, Moore WV 1990 Effect of treatment with biosynthetic growth hormone $(\mathrm{GH})$ on peripheral blood lymphocyte populations and function in growth hormone deficient children. J Clin Endocrinol Metab 70:1756-1760

43. Rapaport R, Oleske J, Ahdieh H, Skuza K, Holland BK, Passannante MR, Denny T 1987 Effects of human growth hormone on immune functions: in vitro studies on cells of normal and growth hormone-deficient children. Life Sci 41:2319-2324

44. Abbassi V, Bellanti JA 1985 Humoral and cell-mediated immunity in growth hormone-deficient children: effect of therapy with human growth hormone. Pediatr Res 19:299-301

45. Church JA, Costin G, Brooks J 1989 Immune functions in children treated with biosynthetic growth hormone. J Pediatr 115:420-423

46. Bozzola M, Maccario R, Cisternino M, De Amici M, Valtorta A, Moretta A, Biscaldi I, Schimpff RM 1988 Immunological and endocrinological response to growth hormone therapy in short children. Acta Paediatr Scand 77:675680

47. Etzioni A, Pollack S, Hochberg Z 1988 Immune function in growth hormonedeficient children treated with biosynthetic growth hormone. Acta Paediatr Scand 77:169-170

48. Bozzola M, Cisternino M, Valtorta A, Moretta A, Biscaldi I, Maghnie M, De Amici M, Schimpff RM 1989 Effect of biosynthetic methionyl growth hormone $(\mathrm{GH})$ therapy on the immune function in $\mathrm{GH}$-deficient children. Horm Res 31:153-156

49. Bozzola M, Valtorta A, Moretta A, Cisternino M, Biscaldi I, Schimpff RM 1990 In vitro and in vivo effect of growth hormone on cytotoxic activity. J Pediatr 117:596-599

50. Crist DM, Kraner JC 1990 Supplemental growth hormone increases the tumor cytotoxic activity of natural killer cells in healthy adults with normal growth hormone secretion. Metabolism 39:1320-1324

51. Mercola KE, Cline MJ, Golde DW 1981 Growth hormone stimulation of normal and leukemic human T-lymphocyte proliferation in vitro. Blood 58:337-340

52. Schimpff R-M, Repellin A-M, Salvatoni A, Thieriot-Prevost G, Chatelain P 1983 Effect of purified somatomedins on thymidine incorporation into lectin-activated human lymphocytes. Acta Endocrinol 102:21-26

53. Geffner ME, Bersch N, Lippe BM, Rosenfeld RG, Hintz RL, Golde DW 1990 Growth hormone mediates the growth of T-lymphoblast cell lines via locally generated insulin-like growth factor-1. J Clin Endocrinol Metab 71:464-469

54. Guler H-P, Zapf J, Scheiwiller E, Froesch ER 1988 Recombinant human insulin-like growth factor 1 stimulates growth and has distinct effects on organ size in hypophysectomized rats. Proc Natl Acad Sci USA 85:48894893

55. Binz K, Joller P, Froesch P, Binz H, Zapf J, Froesch ER 1990 Repopulation of the atrophied thymus in diabetic rats by insulin-like growth factor 1. Proc Natl Acad Sci USA 87:3690-3694

56. Timsit J, Savino W, Safieh B, Chanson P, Gagnerault MC, Bach JF, Dardenne M 1992 Growth hormone and insulin-like growth factor-I stimulate hormonal function and proliferation of thymic epithelial cells. J Clin Endocrinol Metab 75:183-188

57. Krentz AJ, Koster FT, Crist D, Finn K, Boyle PJ, Schade DS 1991 Beneficial anthropometric effects of human growth hormone in the treatment of AIDS Clin Res 39:220A (abstr)

58. Mulligan K, Grunfeld C, Hellerstein M, Schambelan M 1992 Growth hormone treatment of HIV-associated catabolism. FASEB J 6:A1942 (abstr)

59. Murphy WJ, Tsarfaty G, Longo DL 1992 Growth hormone exerts hematopoietic growth-promoting effects in vivo and partially counteracts the myelosuppressive effects of azidothymidine. Blood 80:1443-1447 